\title{
Saúde mental de docentes universitários em tempos de pandemia
}

I 1 Andrey Ferreira da Silva, ${ }^{2}$ Fernanda Matheus Estrela,

${ }^{3}$ Nayara Silva Lima, ${ }^{4}$ Carlos Tibúrcio de Araújo Abreu I

1 Universidade Federal da Bahia. Salvador-BA, Brasil (silva.andrey1991@hotmail.com). ORCID: 0000-0002-1038-7443
${ }^{2}$ Universidade Estadual de Feira de Santana. Feira de Santana-BA, Brasil (nanmatheus@yahoo.com.br).0RCID: 0000-0001-7501-6187
${ }^{3}$ Secretaria Municipal de Saúde de Salvador. Salvador-BA, Brasil (slnayaraa@gmail.com). ORCID: 0000-0001-7911-012X
${ }^{4}$ Secretaria de Educação de Atalaia. Maceió-AL, Brasil (ctabreu7@gmail.com). ORCID: 0000-0002-0607-5906

Recebido em: 25/04/2020

Aprovado em: 29/04/2020

Revisado em: 30/04/2020

DOI: http://dx.doi.org/10.1590/S0103-73312020300216

A pandemia de Covid-19, causada pelo SARS-Cov-2, tem se propagado de forma devastadora, causando diversos impactos na sociedade, relacionados a morbimortalidade e adoção de medidas de isolamento de toda população para conter a transmissibilidade do vírus. Sendo assim, com as novas portarias do Ministério da Educação, foi necessário que as instituiçóes de nível superior e seus docentes criassem estratégias de operacionalização da educação à distância, de modo a prover um ensino inovador. Diante tal cenário, os educadores se expóem a diversas situaçôes e pressóes das instituiçôes, o que reverbera no adoecimento, principalmente relacionado à saúde mental.

O novo coronavírus, nomeado SARS-CoV-2, foi anunciado ao mundo em 31 de dezembro de 2019, e diante das proporçôes de contágio e elevados números de mortem em março de 2020, a Organização Mundial da Saúde (OMS) já declarava Emergência de Saúde Pública de Importância Internacional, uma pandemia (ORTIZ, 2020; DANIEL, 2020). O número de infectados mundialmente já ultrapassa os 2 milhóes, além de serem registrados até meados de abril de 2020, ao menos, 160 mil óbitos por complicações da doença (WHO, 2020). No Brasil, contabilizando 
também desde o surgimento até abril, são mais de 33 mil casos confirmados e 2 mil óbitos, o que coloca o país na $8^{a}$ posição mundial em mortes (RANKBR, 2020). Cabe destacar que, mesmo assintomáticas, as pessoas podem estar infectadas e serem veículos de transmissão, o que sinaliza para a necessidade de intensificar medidas de isolamento de toda a população, inclusive nas instituições de ensino superior.

O cenário provocado pela pandemia fez com que os gestores das faculdades e universidades tivessem que colocar em prática as normativas preconizadas pela Portaria no 345/2020 do Ministério da Educação, que autoriza, em caráter excepcional, a substituição das disciplinas presenciais, em andamento, por aulas que utilizem meios e tecnologias de informação e comunicação, de modo a dar continuidade ao semestre e, consequentemente, ao ano letivo (JOWSEY et al., 2020). Dessa forma, surgem desafios para os docentes relacionados ao aprendizado do manuseio das tecnologias da informação e comunicação na modalidade de ensino à distância (EaD), para estimular os discentes na construção e busca do conhecimento e assim garantir a finalização do ano letivo.

$\mathrm{Na}$ área da saúde, principalmente nos cursos de Enfermagem, as portarias do Ministério da Educação nos 2.253/2001, 4.059/2004 e 1.134/2016 oficializam a possibilidade de oferta de componentes curriculares na modalidade à distância. Isso se refere a apenas $20 \%$ da carga horária do curso e reflete as dificuldades do processo de ensino-aprendizagem dos discentes, considerando que cerca de $40 \%$ do curso se realiza de forma prática, em contato com pacientes, patologias e o cuidado nesse contexto (BEZERRA, 2020; CORREA, 2020). Entretanto, esse novo contexto, marcado por incertezas, fez com que os gestores repensassem em estratégias pedagógicas e acadêmicas, de modo a preservar os princípios da educação, suas diretrizes e leis, considerando a possibilidade da inclusão de novas tecnologias de informação e comunicação e uso de plataformas digitais.

Em que pese a necessidade de dar seguimento ao ano letivo e considerando o tripé universitário do ensino, pesquisa e extensão, os docentes precisam se adaptar, juntamente com suas rotinas de casa, considerando que precisam dar conta de atividades domésticas, visto que muitas secretárias também seguem a regra posta pelo governo do isolamento social. Esse contexto também revelou que muitos docentes não estavam preparados para incluir novas tecnologias, considerando que sua formação não comtempla o uso de tecnologias digitais, sendo necessárias 
atualizaçôes e capacitaçôes de modo a preservar a qualidade do ensino (GONZALEZ et al., 2020, KIM et al., 2020). Urge, assim, que os gestores pensem em capacitaçóes para docentes no contexto da pandemia.

Muitas vezes, por não conseguir atingir os objetivos propostos pela instituição, e devido às diversas pressôes relacionadas ao manuseio das tecnologias, gravaçôes de aulas, os docentes acabam adoecendo. Estudos revelam que as tecnologias digitais precisam transcender a educação bancária de difusão de conhecimentos, devendo ser criados espaços de participação, reflexão dialógica, desenvolvendo o raciocínio clínico, crítico, diferenciado (MCKIMM et al., 2020). Em contrapartida, pesquisas internacionais já revelam o adoecimento docente expresso pelas incertezas, estresses, ansiedade e depressão, levando à síndrome do esgotamento profissional (ARAÚJO et al., 2020).

Estudo chinês revela inúmeros docentes adoecidos mentalmente pela Covid-19, devido a transtorno depressivo leve, transtorno afetivo bipolar, ansiedade generalizada, transtorno de adaptaçáo e síndrome de burnout ou síndrome do esgotamento profissional (WANG; WANG, 2020). Esse contexto revela que os professores universitários estão inseridos em um ambiente propício ao adoecimento mental pelos impactos da Covid-19, seja pelas notícias jornalísticas de morbimortalidade, seja pelas pressóes oriundas das instituiçóes de ensino superior relacionadas ao uso das tecnologias digitais, somadas a sua vida conjugal, materna e doméstica e tantas outras atribuiçôes que lhes são conferidas (SHAW, 2020).

Éimportante que os gestores repensem capacitaçôes em EaD que instrumentalizem docentes para o uso das tecnologias no processo ensino-aprendizagem dos discentes. Além disso, sugere-se que sejam criados espaços virtuais compostos de equipes multiprofissionais, para o atendimento aos docentes por meio de atividades de relaxamento, inclusive voltados para a saúde mental desses trabalhadores, para que eles possam dividir suas angústias e minimizar o turbilhão de sentimentos que permeia suas vidas no contexto da pandemia.

\section{Referências}

ARAÚJO, F.J.O et al. Impact of Sars-Cov-2 and its Reverberation in Global Higher Education and Mental Health. Psychiatry Research, v. 288, p. 112977, 2020. Disponível em: <https:// linkinghub.elsevier.com/retrieve/pii/S0165178120307009>. Acesso em: 4 maio 2020. 
BEZERRA, I.M.P. State of the art of nursing education and the challenges to use remote technologies in the time of Corona Virus Pandemic. Journal of Human Growth and Development, v. 30, n. 1, p. 141-147, 2020. Disponível em: <http://revistas.marilia.unesp.br/index.php/jhgd/ article/view/10087>. Acesso em: 4 maio 2020.

CORREA, S.M.M. La innovación educativa en los tiempos del Coronavirus. Salutem Scientia Spiritus (En línea), v. 6, n. 1, 2020. Disponível em: https://revistas.javerianacali.edu.co/index. php/salutemscientiaspiritus/article/view/2290/2863. Acesso em: 4 maio 2020.

DANIEL, S.J. Education and the COVID-19 pandemic. PROSPECTS, 2020. Disponível em: <http://link.springer.com/10.1007/s11125-020-09464-3>. Acesso em: 4 maio 2020.

GONZALEZ, T. et al. Influence of COVID-19 confinement in students performance in higher education. arXiv.org, 2020. Disponível em: https://arxiv.org/abs/2004.09545. Acesso em: 4 maio 2020.

JOWSEY, T. et al. Blended learning via distance in pre-registration nursing education: A scoping review. Nurse Education in Practice, v. 44, p. 102775, 2020. Disponível em: <https:// linkinghub.elsevier.com/retrieve/pii/S147159531930112X>. Acesso em: 4 maio 2020.

KIM, S. et al. School Opening Delay Effect on Transmission Dynamics of Coronavirus Disease 2019 in Korea: Based on Mathematical Modeling and Simulation Study. Journal of Korean Medical Science, v. 35, n. 13, 2020. Disponível em: <https://jkms.org/DOIx.php?id=10.3346/ jkms.2020.35.e143>. Acesso em: 4 maio 2020.

MCKIMM, J. et al. Health Professions' Educators' Adaptation to Rapidly Changing Circumstances: The Ottawa 2020 Conference Experience. MedEdPublish, v. 9, n. 1, 2020. Disponível em: <https://www.mededpublish.org/manuscripts/2936>. Acesso em: 4 maio 2020. ORTIZ, P.A. Teaching in the time of COVID-19. Biochemistry and Molecular Biology Education, 2020. Disponível em: <http://doi.wiley.com/10.1002/bmb.21348>. Acesso em: 4 maio 2020.

RANKBR. Pandemia do Coronavirus no Brasil. Rankbr, 2020. Disponível em: https://www. rankbr.com.br/covid19br. Acesso em: 18 abr 2020.

SHAW, K. Colleges expand VPN capacity, conferencing to answer COVID-19. Network World (online), Apr 2, 2020. Disponível em: https:/www.networkworld.com/article/3535415/ colleges-expand-vpn-capacity-conferencing-to-answer-covid-19.html. Acesso em: 4 maio 2020. WANG, J.; WANG, Z. Strengths, Weaknesses, Opportunities and Threats (SWOT) Analysis of China's Prevention and Control Strategy for the COVID-19 Epidemic. International Journal of Environmental Research and Public Health, v. 17, n. 7, p. 2235, 2020. Disponível em: <https:// www.mdpi.com/1660-4601/17/7/2235>. Acesso em: 4 maio 2020.

WORLD HEALTH ORGANIZATION. Coronavirus (Covid-19): Painel de emergência de saúde da WHO. WHO, 2020. Disponível em: https://covid19.who.int/. Acesso em: 22 abr 2020. 